Asian-Australasian Journal of

Food Safety and Security

ISSN 2523-1073 (Print) 2523-2983 (Online)

www.ebupress.com/journal/aajfss

\title{
Article
}

\section{Implementation of code of practices (CoP) in selected poultry farms of Bangladesh}

\author{
AHM Taslima Akhter ${ }^{1}$, SK Shaheenur Islam ${ }^{2 *}$, Md Abu Sufian ${ }^{2}$, Monowar Hossain ${ }^{1}$, Shah Md. Mahfuzur \\ Rahman $^{1}$, S. M. Lutful Kabir ${ }^{3}$, Md Gias Uddin ${ }^{4}$, Shah Monir Hossin ${ }^{1}$ and Md Mehedi Hossain ${ }^{2}$ \\ ${ }^{1}$ Food Safety Unit, Institute of Public Health, Mohakhali, Dhaka-1212, Bangladesh \\ ${ }^{2}$ Department of Livestock Services, Krishi Khamar Sarak, Farmgate, Dhaka-1215, Bangladesh \\ ${ }^{3}$ Department of Microbiology and Hygiene, Bangladesh Agricultural University, Mymensingh-2202, Bangladesh \\ ${ }^{4}$ Bangladesh Livestock Research Institute (BLRI), Savar, Dhaka, Bangladesh
}

*Corresponding author: SK Shaheenur Islam, Department of Livestock Services, Krishi Khamar Sarak, Farmgate, Dhaka-1215, Bangladesh. E-mail: s_islam73@live.com

Received: 17 October 2018/Accepted: 08 November 2018/ Published: 29 November 2018

\begin{abstract}
The overuse of antibiotics, chemicals and as well as lack of farm biosecurity and good hygiene practices in poultry production are considered to be contributors for occurring foodborne illness and many significant public health threats reported in both developed and developing countries nowadays. Considering the above, a piloted food safety activity was implemented jointly by the Department of Livestock Services and FAO-Food Safety program, Bangladesh in twenty-five selected poultry (broiler) dense subdistricts of the country. Good Agriculture Practices (GAP) and Good Hygiene Practices (GHP) related five (microbial) plus five (chemical) Code of Practices (CoP) were adopted at the farm level $(\mathrm{N}=500)$ through farmers' motivation and intensive participatory training program. It was found that average production cost reduces, the feed conversion ratio decreases and mortality rate decreases that convince increase farm profitability in the bestpracticed farms $(\mathrm{n}=81)$. In conclusion, Good Agriculture Practices (GAP) and Good Hygiene Practices (GHP) through certifying key control measures can increase profitability in broiler farming and CoP adapted farms found to be less public health hazardous than non-CoP farms in light of food safety and public health grounds.
\end{abstract}

Keywords: food safety; poultry value chain; code of practices; Bangladesh

\section{Introduction}

The poultry sector has been grown during the 1980s in Bangladesh and taken its full shape in the recent decade. The country has 275.18 million chickens and 54.74 million ducks (DLS, 2016). About 7-8 million people, directly and indirectly, are being involved in this sector, of which 40 percent are women. At present, total investment in this sector amounting 25,000 million BDT(Equiv. 325.00 million USD) and that would be escalated to 50,000 million BDT by 2020 (WPSA, BB, 2017). The national consumption by the year 2020 of poultry meat and chicken eggs is projected to be 307 thousand metric tons and 5,866 million pieces respectively (Yunus et al., 2008). This sector is holding potential for expansion, which would generate more jobs and increase incomes through expansion of production and processing.

In Bangladesh, a considerable number of the foodstuffs manufactured or processed are deliberated to be less safe for consumption or scope of adulteration to varying degrees that poses risk to public health (Ali, 2013). Each year millions of people in Bangladesh suffer from foodborne diseases caused by consumption of contaminated food (Sarker et al., 2018). Contamination across the food chain due to lack of awareness of good practices among the actors in the chain is evident. This hinders to access of Bangladeshi agricultural products to wider regional and international markets. Therefore, the ampoule of scope to address food safety issues across the chain is necessitated. 
The poultry farming system in Bangladesh is diversified and has been classified into 4 sectors, are sector 1: industrial integrated system with high level of biosecurity and birds/products marketed commercially; Sector 2: Commercial poultry production system with moderate to high biosecurity and birds/products usually marketed commercially. About $20 \%$ of farms under this category; sector 3: Commercial poultry production system with low to minimal biosecurity and birds/ products entering live bird markets. About 55-60\% of farms included under this category and sector 4: village or backyard production with minimal biosecurity and birds/products consumed locally (Dolberg, 2008).

In view of significance for implementing food control guidelines, the FAO food safety program named "Improving food safety in Bangladesh" had been implemented a piloted poultry food safety activity in 25 selected districts throughout the country in collaboration with Department of Livestock Services (DLS). The objective of the program was to understand the impact of food safety control measures towards developing a food control guideline for the poultry value chain that would be appropriate for the country context. The guideline will foster to access of poultry and poultry products in the international market through implementing Good Agriculture Practices (GAP), Good Hygienic Practice (GHP) in poultry production system. Moreover, the situation of microbial contamination in the different tier of poultry supply chain also has been assessed in this study.

\section{Material and Methods}

\subsection{Study area and study design}

A cross-sectional study was conducted in 25 selected sub-districts of 13 districts comprising entire geographical locations of Bangladesh. Twenty (20) broiler farms from each Upazila totaling 500 farms in sector 3 were enrolled in this study with a farm size 500 to 5000. The farmers of the registered farms had been trained and motivated for implementing best farm practices on five plus five Code of practices (CoP) regarding microbiological and chemical parameters.

\subsection{Data collection, management and analysis}

The data on farms practices were recorded in the formatted farm record book for each production cycle of CoP farms. The data comprises the farm practices in the light of biosecurity measures, inputs used for broiler production. The grading system has applied for recorded farm practices that were converted to a percentage for interpretation.

Data for each production cycle were captured from the farm record book using the scoring of the target parameters by trained veterinarians on monthly basis and sent to the central server via ODK software installed in the android mobile phone. The pathway of ODK based data monitoring is shown in Figure 2.

Later, the data were exported and analyzed using Microsoft Excel® tools. Of 500 farms ( $=500)$, eighty-one $(n=81)$ farms ensured consistent data for the three (3) subsequent production cycles and these data were used for further analysis and interpretation. A comparative analysis between different production cycles (batch 1, 2 and 3 ) had also been performed for evaluating Code of practices ( $\mathrm{CoP})$. However, comparative analysis between the baseline and subsequent production cycles (batch 1,2 \& 3) were also made a few parameters where appropriate using Excel tools®.

\subsection{Sample collection, sample testing}

Twelve number of project intervened broiler farms (Dhaka, Tangail, Joypurhat district) were included in this study. However, to understand the microbial prevalence (Salmonella and Campylobacter) the other part of the supply chain were also addressed in this study that included through a convenient sampling technique from 12 number of poultry carrying transports and 4 Live bird markets (LBMs). Thus, the samples were collected from live broiler, broiler meat, LBM environmental sample, broiler carrying vehicle. A number of 758 samples were collected from all strata of the supply chain. Moreover, antimicrobial residues (Oxytetracycline, Ciprofloxacin and Enrofloxacin) also had been measured in the boiler meat $(n=68)$ using HPLC to detect the presence of antibiotic contamination. The samples were also collected from the non-CoP farms for inferential analysis with the CoP farms. Data for laboratory test results was also analyzed statistically using Microsoft Excel® tools.

\section{Results}

Code of Practices i.e. five plus five Control measures (both chemical and microbial) were implemented in the piloted broiler farms through training and motivation of Lead Farmers (LF). The trend of control measures both microbiological and chemical parameters were improved gradually in the successive production cycles was found in this study. 
3.1. Perimeter fencing $(n=81)$

Perimeter fencing was improved gradually towards the subsequent production shown in Figure 3 . At the batch 1 the average score for perimeter fencing was $67.47 \%$ that upgraded to approximately at maximum in the batch 3 $(96.27 \%)$.

\subsection{Netting of the farm $(n=81)$}

This practice was sharply progressed in the subsequent production batches show in figure 4 . In the batch-1 the average score for netting was $83.85 \%$ that improved to nearly maximum $(93.85 \%)$ at the batch 3 .

\subsection{Day old chicks collection (DOCs) $(\mathrm{n}=81)$}

Day Old Chicks (DOC) collection was improved in the subsequent production cycle (figure 5). In the batch-1 the average score for Day Old Chick (DOC) was $78.40 \%$ that improved to maximize (87\%) at the batch 3 .

\subsection{Feed purchase from approved source $(n=81)$}

Feed purchase from the reputed source/ company also had been improved in the subsequent product cycle shown (Figure 6). Feed purchase from the approved source was also improved over the production cycle from $78.40 \%$ to $87.70 \%$. The improvement of CoPs considering microbiological and chemical parameters over the production batches shown in Figure 7.

\subsection{Footwear clean at entry $(n=81)$}

The farmers motivated for best farm practices like entry in the farm with clean footwear gradually improves in the later production cycle shown in Figure 8. The average score for the footwear clean entry for the initial batch was $66.5 \%$ that upgraded to the batch $3(81.5 \%)$.

\subsection{All in all out practice $(n=81)$}

All in all out practice were satisfactorily increased in the succeeding production cycles shown in Figure 9. This practice was found to be better comparatively than the other practices as the average score for the first batch was $94.4 \%$ that maximized to $99.94 \%$ at the batch 3 .

\subsection{Farm record keeping $(n=81)$}

Record keeping of farm activities was improved gradually in the successive batches (Figure 10). The average score for the farm record keeping in the batch 1 was $75 \%$ that improved to $80 \%$ in batch 3 .

\subsection{Cleaning and sanitation $(n=81)$}

Cleaning and sanitation practice was advanced in the subsequent batches shown in Figure 11. The average score for Cleaning and sanitation practice in batch 1 was $85 \%$ that improved to $92 \%$ in batch 3 .

\subsection{Farm productivity}

\subsubsection{Average production cost $(n=81)$}

Average production cost comparatively reduces in the subsequent batches as shown in Figure 12. At the batch 1 the average production cost / Kg broiler was BDT 109.98 and it lowered down sharply to 100.16 and 103.09 in the next two production cycles (batch 2 and 3 ).

\subsubsection{Feed conversion ratio $(F C R)$ improves $(n=81)$}

FCR improves gradually in the following production cycles has been shown in the figure 13. At the baseline it was 1.89 and it lowered down to 1.61 (batch 1), 1.52 (batch 2) and 1.6 (batch 3) in the three following production cycle.

\subsubsection{Medicine cost $(n=81)$}

Medicine cost reduces in the subsequent production cycle shown in figure 14. At the baseline the average production cost/ Kg of broiler was BDT 6.09 and it lowered down to BDT 5.03 (batch-1), 4.41(batch-2) and 4.08(batch-3) in the three following production cycles.

\subsubsection{Mortality rate $(n=81)$}

Mortality rate comparatively reduced in the subsequent production cycle shown in figure 15. 
The baseline mortality rate was $5.3 \%$ that declined gradually in the successive production cycles to $4.82 \%$, $4.76 \%$ and $4.00 \%$ respectively.

\subsubsection{Average profit $/ \mathrm{Kg}(\mathrm{n}=81)$}

The average profit $/ \mathrm{Kg}$ of broiler production considerably increased in the following production cycle shown in Figure 16. At the batch 1 the profit/Kg of broiler was BDT 9.23 and it improved comparatively in the next two batches to BDT 14.05 and 12.22 respectively.

\subsection{Sample testing result}

A number of 858 samples were collected and tested against selected parameters. The samples were collected as cloacal swab, feed, water, whole carcass, transport/vehicle and LBM's environmental swab and tested shown in Table 2 .

\subsubsection{Prevalence of Salmonella spp.}

The prevalence of Salmonella spp. 44.80\% (43/96) in cloacal sample, 6.67\% (4/60) in feed sample, 10\% (5/50) in water sample, $25 \%(9 / 36)$ in whole carcass were estimated through the procedure described by Nordic Committee on Food Analysis, (1991) and Van der Giessen et al., (2006). And that found to be at lower prevalence than the non-CoP adapted farms. The CoP adopted farms has shown significantly lower likelihood Salmonella spp. contamination than Non-CoP farms (feed, table 4, OR=0.21 95\% CI=0.06-0.72, $p=0.0129$ ). The prevalence of Salmonella spp. was 36.36\% (4/11) in transport/ vehicle and $16.67 \%(1 / 6)$ in LBM's environmental sample were confirmed.

\subsubsection{Prevalence of Campylobacter spp.}

The prevalence of Campylobacter spp. was $27.08 \%$ (26/96) in cloacal sample, 1\% (1/60) in feed sample, $6 \%$ (3/50) in water sample, $19.44 \%(7 / 36)$ in whole carcass were assessed in CoP adapted farms found through the procedure described by Shiramaru et al. (2012). This result has revealed to be lower prevalence than non-CoP farms (Table 2). The CoP adapted farms has shown significantly lower likelihood Campylobacter spp. contamination than Non-CoP farms (cloacal swab, feed, water, whole carcass, hand rinse water, table-2). The prevalence of Campylobacter spp. was 0\% (0/11) in transport/ vehicle swab, 5.77\% (3/52) in chicken meconium and $16.67 \%(1 / 6)$ in LBM environmental sample were found. The sample test results for CoP intervened and non-COP farms shown in Table 2.

\subsubsection{Antimicrobial residue detected}

The prevalence of Oxytetracycline 33.82\% (23/68), Ciprofloxacine 17.65\% (12/68) and Enrofloxacine 11.76\% $(8 / 68)$ were in the meat sample of CoP adapted farms shown in Table 3.

\subsubsection{Antimicrobial residue level detected}

The average level of oxytetracycline was $76.60 \mu \mathrm{g} / \mathrm{kg}$ of broiler meat sample with a range $0.36-156.09 \mu \mathrm{g} / \mathrm{kg}$ meat; whereas the average level of ciprofloxacin was $67.88 \mu \mathrm{g} / \mathrm{kg}$ of meat with a range $0.69-156.45 \mu \mathrm{g} / \mathrm{kg}$. The level of antimicrobial contamination (Oxyteracycline and Ciprofloxacin) in the meat samples $(n=25)$ has been shown in Figure 17 and Figure18.

Table 1. Code of practices (CoP) regarding microbiological and chemical parameters addressed at the farm level.

\begin{tabular}{ll}
\hline Category & Code of practices (CoPs) \\
\hline & Protect poultry flock with good biosecurity \\
& Use safe production inputs \\
Microbiological & Apply Good Animal Husbandry Practices(GAP) \\
& Practice Good Personal Hygiene \\
& Practice Good Poultry Waste Management and Environmental control \\
\hline & Purchase good quality feed, free from chemical hazards \\
& Purchase mineral and vitamin supplements from reliable sources and free from chemical hazards \\
Chemical & Use clean water free from harmful chemicals \\
& Use antibiotics under veterinary supervision \\
& Protect feed and water from contaminants \\
\hline
\end{tabular}


Table 2. Sample tested results for microbial (Salmonella and Campylobacter) parameters.

\begin{tabular}{|c|c|c|c|c|c|}
\hline \multirow[b]{2}{*}{ Sample type } & \multirow[b]{2}{*}{ Parameters } & \multicolumn{2}{|c|}{ Sample tested } & \multicolumn{2}{|c|}{ Prevalence (95\% CI) } \\
\hline & & $\begin{array}{l}\text { CoP } \\
\text { farms }\end{array}$ & $\begin{array}{l}\text { Non CoP } \\
\text { farms }\end{array}$ & CoP farms & Non CoP farms \\
\hline \multicolumn{6}{|l|}{ Poultry farms } \\
\hline \multirow{2}{*}{ Chicken meconium } & Salmonella spp. & $6 / 52$ & - & $11.54(4.4-23.4)$ & - \\
\hline & Camphylobactor spp. & $3 / 52$ & - & $5.77(1.2-15.9)$ & - \\
\hline \multirow{2}{*}{ Cloacal swab } & Salmonella spp. & $43 / 96$ & $32 / 64$ & $44.80(34.6-55.3)$ & $50(37.23-62.77)$ \\
\hline & Camphylobactor spp. & $26 / 96$ & $34 / 64$ & $27.08(18.5-37.1)$ & $37.5(25.70-50.49)$ \\
\hline \multirow{2}{*}{ Feed } & Salmonella spp. & $4 / 60$ & $8 / 32$ & $6.67(1.8-16.2)$ & $25(11.46-43.50)$ \\
\hline & Camphylobactor spp. & $1 / 60$ & $8 / 32$ & $1(0-9.00)$ & $25(11.46-43.50)$ \\
\hline \multirow{2}{*}{ Water } & Salmonella spp. & $5 / 50$ & $6 / 32$ & $10.00(3.3-21.8)$ & $18.75(7.21-36.44)$ \\
\hline & Camphylobactor spp. & $3 / 50$ & $7 / 32$ & $6(1.3-16.5)$ & $21.88(9.28-39.97)$ \\
\hline \multirow{2}{*}{ Whole carcass } & Salmonella spp. & $9 / 36$ & $7 / 16$ & $25(12.10-42.2)$ & $43.75(19.75-70.12)$ \\
\hline & Camphylobactor spp. & $7 / 36$ & $8 / 16$ & $19.44(8.2-36.0)$ & $50(24.65-75.35)$ \\
\hline \multirow{2}{*}{ Hand rinse water } & Salmonella spp. & $5 / 32$ & $11 / 32$ & $15.62(5.27-32.78)$ & $34.38(18.57-53.19)$ \\
\hline & Camphylobactor spp. & $6 / 32$ & $7 / 32$ & $18.75(7.20-36.43)$ & $21.88(9.28-39.97)$ \\
\hline \multicolumn{6}{|c|}{ Other segment of poultry supply chain } \\
\hline \multirow{2}{*}{ Transport (vehicle) } & Salmonella spp. & $4 / 11$ & - & $36.36(10.9-69.2)$ & - \\
\hline & Camphylobactor spp. & $0 / 11$ & - & $0.00(0-28.5)$ & - \\
\hline Live bird market & Salmonella spp. & $1 / 6$ & - & $16.67(0.4-64.1)$ & - \\
\hline (Environmental swab) & Camphylobactor spp. & $1 / 6$ & - & $16.67(0.4-64.4)$ & - \\
\hline
\end{tabular}

Table 3. Sample tested results for chemical hazards (antimicrobial residues) in CoP farms.

\begin{tabular}{llllll}
\hline Sample type & Antibiotics & Positive & Negative & Total (n) & Prevalence (95\% CI) \\
\hline \multirow{3}{*}{ Meat } & Oxytetracycline & 23 & 45 & 68 & $33.82(22.8-46.3)$ \\
& Ciprofloxacin & 12 & 56 & 68 & $17.65(9.5-28.8)$ \\
& Enrofloxacin & 8 & 60 & 68 & $11.76(5.2-21.9)$ \\
\hline
\end{tabular}

Table 4. Result of univariate logistic regression analysis between project intervened CoP and non-CoP farms as a result of code of practices.

\begin{tabular}{|c|c|c|c|c|c|c|c|}
\hline \multirow{3}{*}{ Sample type } & \multirow{3}{*}{ Parameters } & \multicolumn{4}{|c|}{ Sample tested } & \multirow{3}{*}{$\begin{array}{l}\text { Odds ratio } \\
\text { (95\% CI) }\end{array}$} & \multirow{3}{*}{$p$ value } \\
\hline & & \multicolumn{2}{|c|}{ CoP farms } & \multicolumn{2}{|c|}{ Non CoP farms } & & \\
\hline & & Positive & Negative & Positive & Negative & & \\
\hline \multirow{2}{*}{ Cloacal swab } & Salmonella spp. & 43 & 53 & 32 & 32 & $0.81(0.43-1.81)$ & 0.51 \\
\hline & Camphylobactor spp. & 26 & 70 & 34 & 30 & $0.37(0.19-0.72)$ & 0.003 \\
\hline \multirow{2}{*}{ Feed } & Salmonella spp. & 4 & 56 & 8 & 24 & $0.21(0.06-0.72)$ & 0.0129 \\
\hline & Camphylobactor spp. & 1 & 59 & 8 & 24 & $0.50(0.01-0.25)$ & 0.0003 \\
\hline \multirow[t]{2}{*}{ Water } & Salmonella spp. & 5 & 45 & 6 & 26 & $0.48(0.14-1.70)$ & 0.25 \\
\hline & Camphylobactor spp. & 3 & 47 & 7 & 25 & $0.23(0.6-0.88)$ & 0.032 \\
\hline \multirow{2}{*}{ Whole carcass } & Salmonella spp. & 9 & 27 & 7 & 9 & $0.43(0.13-1.46)$ & 0.1763 \\
\hline & Camphylobactor spp. & 7 & 29 & 8 & 8 & $0.26(0.07-0.90)$ & 0.034 \\
\hline \multirow{2}{*}{ Hand rinse water } & Salmonella spp. & 5 & 27 & 11 & 21 & $0.35(0.11-1.15)$ & 0.08 \\
\hline & Camphylobactor spp. & 6 & 26 & 7 & 25 & $0.82(0.24-2.79)$ & 0.75 \\
\hline
\end{tabular}




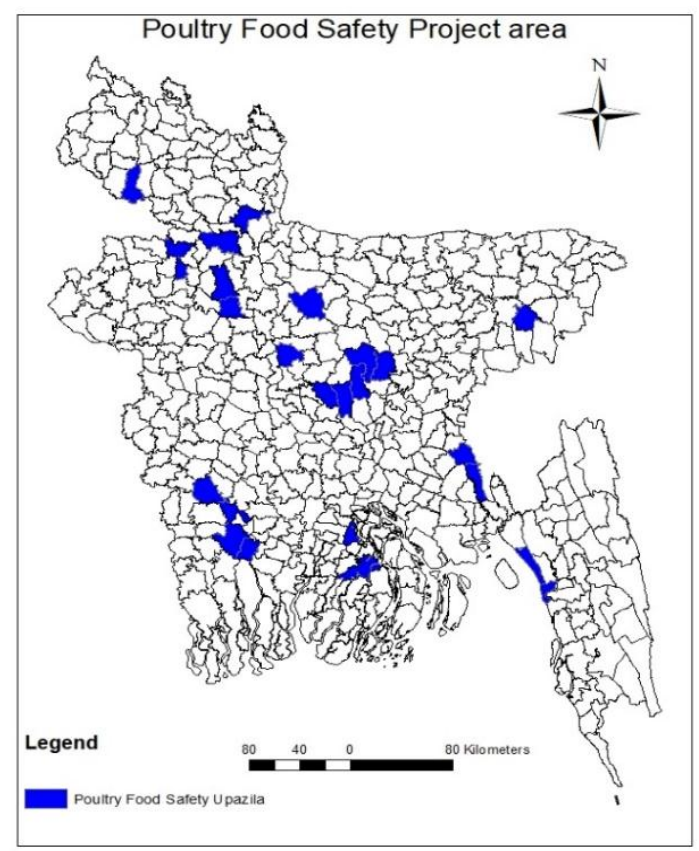

Figure 1. Study area showing 25 upazilas of 13 districts in Bangladesh.

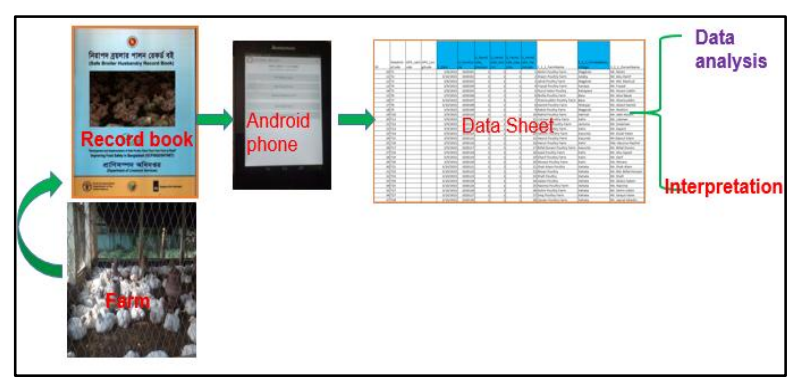

Figure 2. ODK based android data collection and monitoring system.

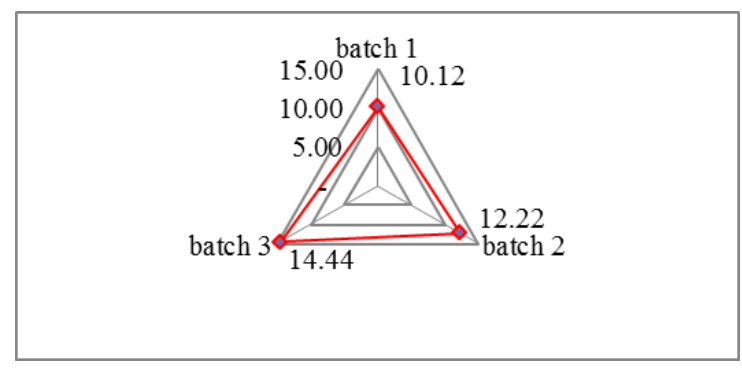

Figure 3. Perimeter fencing.

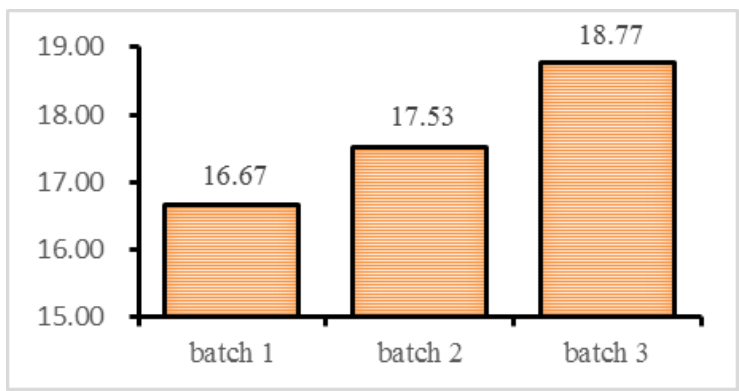

Figure 4. Netting of the farm. 


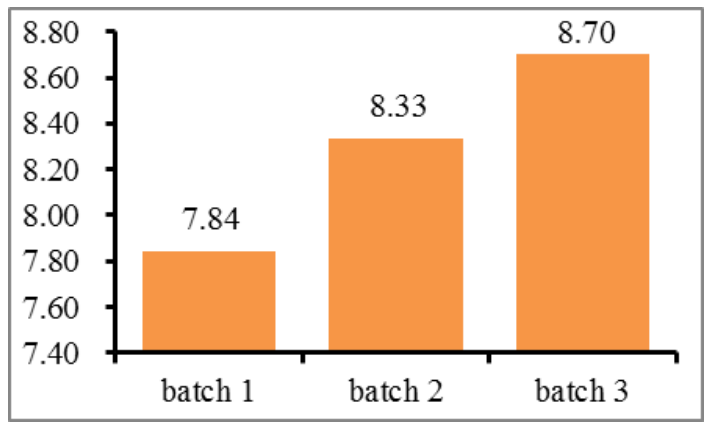

Figure 5. Day old chick collection.

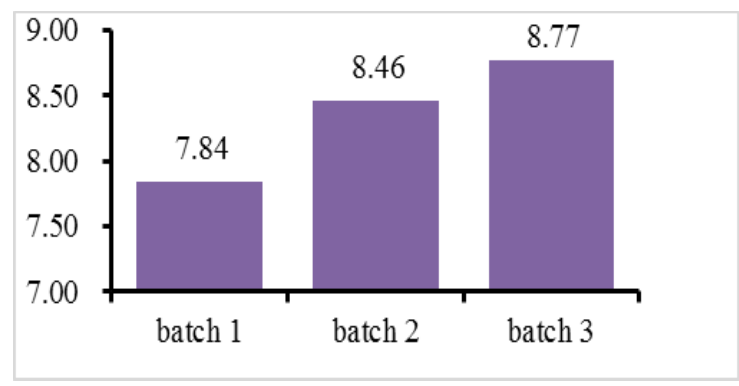

Figure 6. Feed purchase from approved source $(n=81)$.

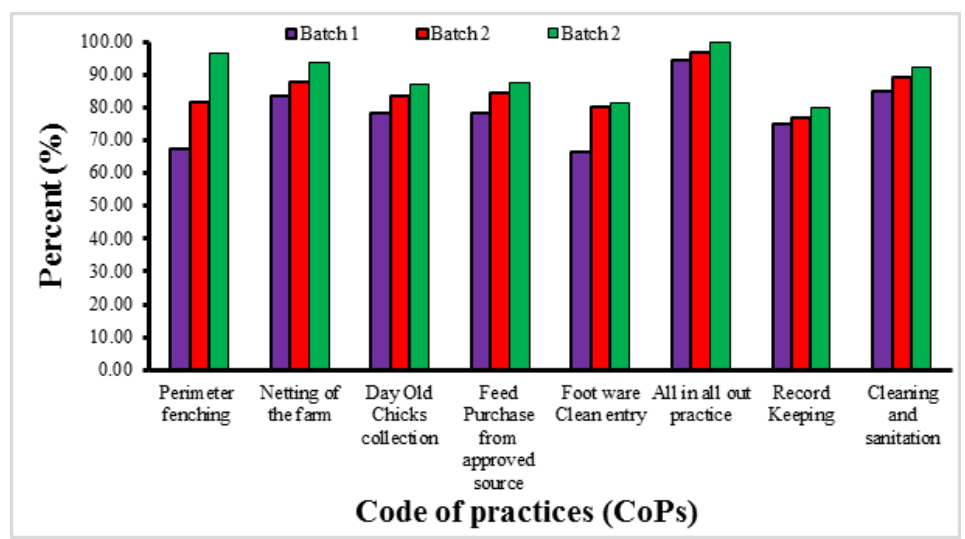

Figure 7. Biological and chemical control measures (CoPs) improve over the successive production cycle at the farm level.

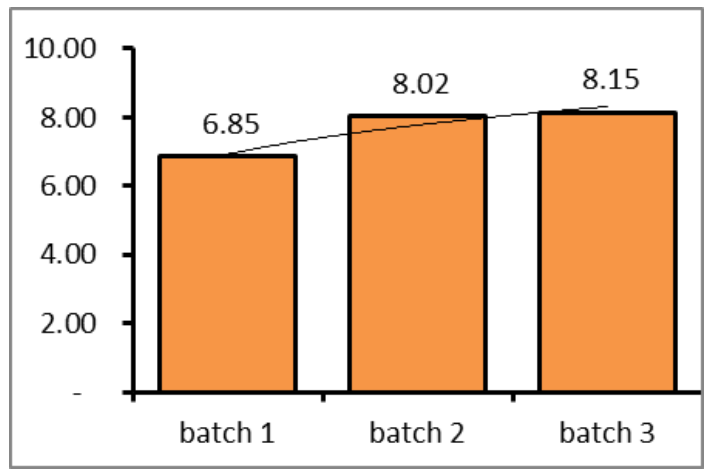

Figure 8. Footwear clean entry. 


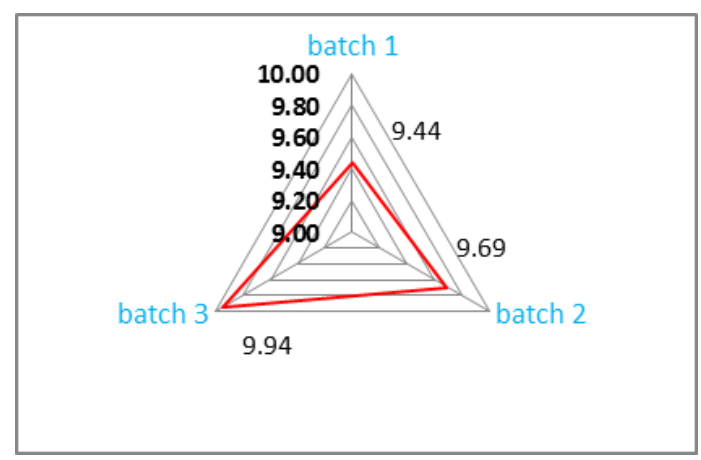

Figure 9. All in all out practice.

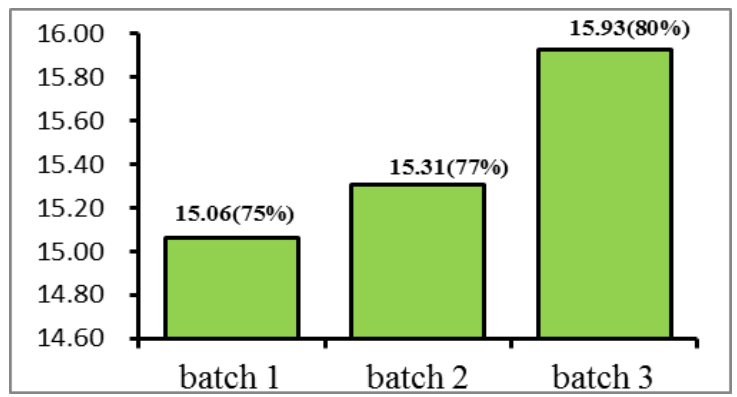

Figure 10. Record keeping of farm activities improves gradually in the successive batches.

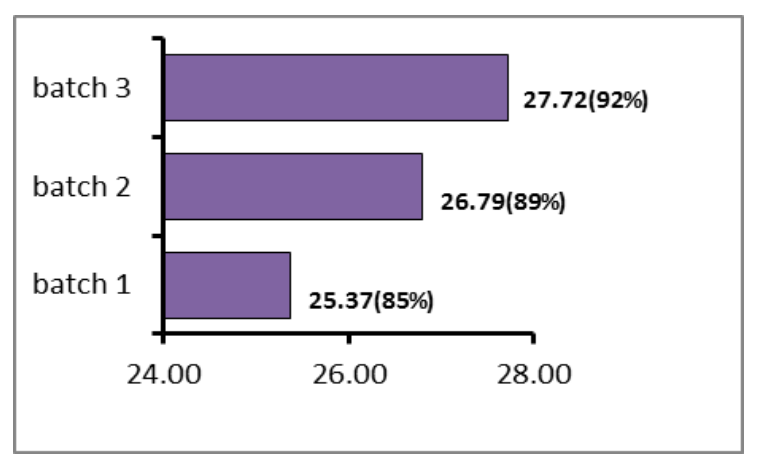

Figure 11. Cleaning and sanitation practice $(\mathbf{n}=81)$.

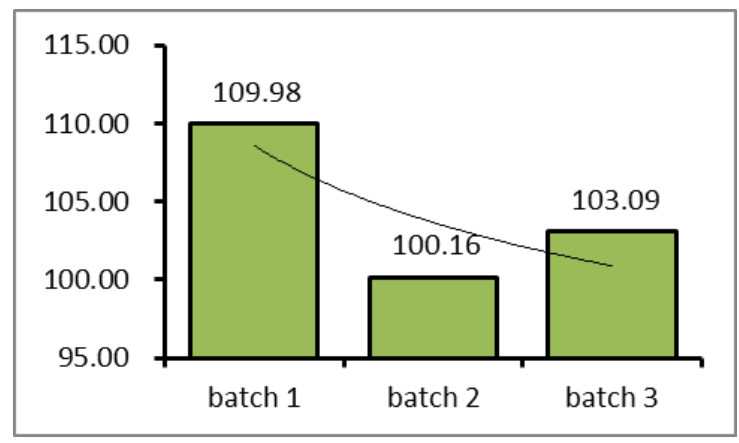

Figure 12. Average production cost reduces. 


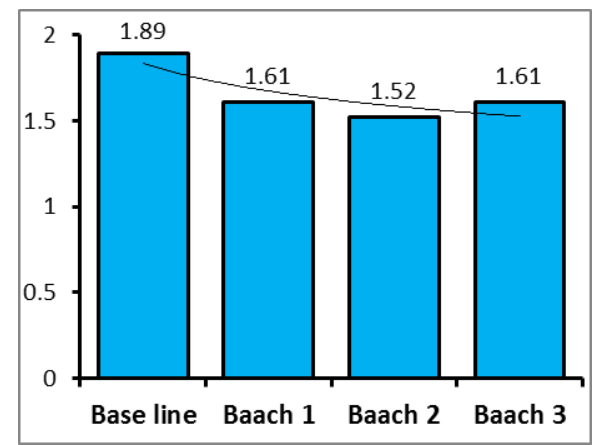

Figure 13. Feed conversion ratio improves.

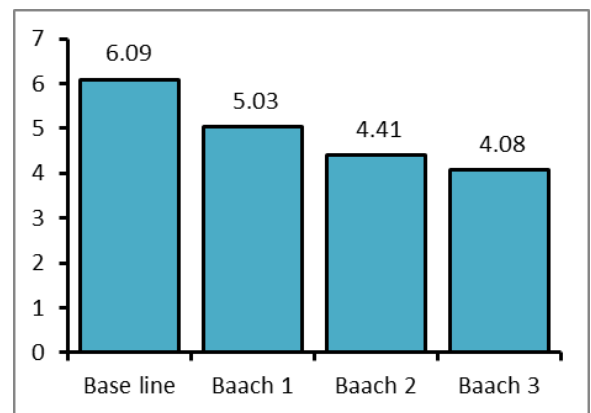

Figure 14. Medicinal cost reduces in the subsequent batches.

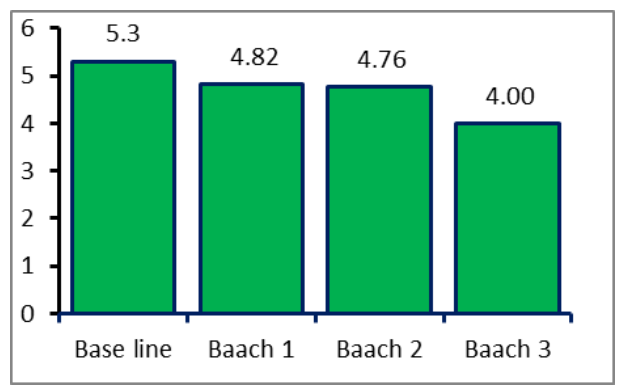

Figure 15. Mortality rate reduce.

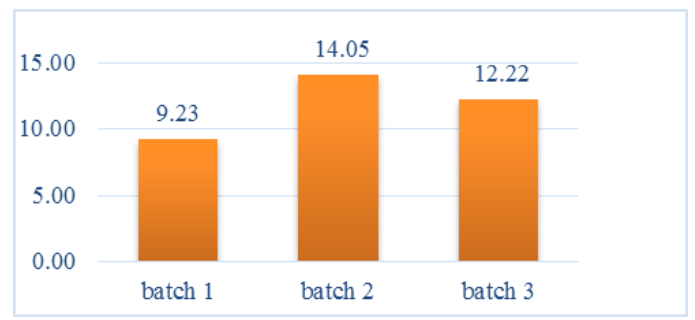

Figure 16. Average profit/ Kg of live bird increases over the batches.

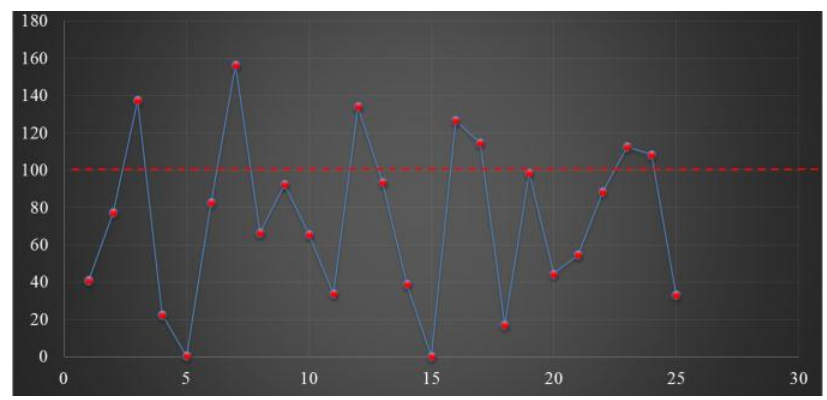

Figure 17. Antimicrobial residue of oxytetracycline $(n=25)$. 


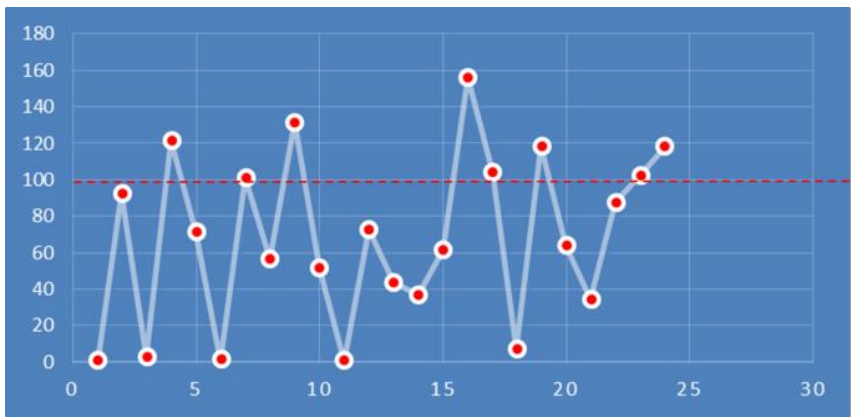

Figure 18. Antimicrobial residue of ciprofloxacin $(n=25)$.

\section{Discussion}

Five plus five Code of Practices (CoPs) (both microbiological and chemical) in the light of biosecurity parameters viz. perimeter fencing, netting of the farm, Day Old Chick (DOC) collection, feed purchase from an approved source, footwear clean entry in the farm, all in all-out practice along with cleaning and sanitation practices were gradually improved in the subsequent production cycle in the CoP adapted farms and found to be effective. Bio-security control measures are important for well performance and quality of poultry production through adoption of good practices (CoPs) in poultry production system (Sharma, 2010). The farmers were trained and motivated on practicing these CoPs and the project supported the piloted broiler farms ensuing for adaptation of the best farm practices through supplying of biosecurity intervention materials.

Perimeter fencing (secondary barrier) and netting (primary barrier) of the farm exclude unwanted entrance of animal and birds that keep the farm healthy. Due to the intervention of food safety piloted activity, the farmers were interested to use perimeter fencing and netting in their farms. However, in Bangladesh context, the adequate space could not be allowed as a secondary fencing applicable in the sector 3 broiler farms, since they are practicing primary netting. The result of perimeter fencing and netting have had a direct effect on farm productivity as these are enabling segregation and maintenance of barriers to delimit the potential chances of carrying infection through animals, birds and influx of contaminated materials to an uninfected farm. Application of these practices farm will avoid most infection (Ratananakorn et al., 2011).

Day Old Chicks (DOCs) collection is an important factor that triggers the profitability of a farm as it minimizes the subsequent infection-related mortality. Due to intervention of food safety activity, the farmers motivated to purchase DOCs from the reliable source as the laboratory tests result supported as less contamination.

Other biosecurity related practices, like; footwear clean entry in the farm, daily cleaning and sanitation practices improves gradually that reduces mortality as it helps to exclude of new infection and ultimately enhances farm productivity. Similarly, all in all-out practice causes the barrier that failure sustains infection in the farm for a long time that gradually improves in the following production cycles. The cumulative effects of all practices the mortality rate decreases in the subsequent production cycle, feed conversion ratio comparatively improves gradually, the medicinal cost decreased sharply that have had a direct impact on average production cost of broiler production. The study confirmed that CoP adapted farms have significantly lower risk of bacterial contamination (Salmonella and Campylobacter) than Non-CoP farms and thus CoPs will reduce the public health related hazards.

Though there was less/no baseline information for assessing the microbial contamination in whole strata of the supply chain. However, it has been presumed that the prevalence of Salmonella spp. in the cloacal sample was 44.79\% that was considerable lower than the other study in Bangladesh (Naurin et al., 2013). The lead farmers have adapted five key microbial control measures that reduce microbial load in the farm level. Similarly, the Campylobacter spp. prevalence was found to be lower level than the earlier study in Bangladesh (Kabir et al., 2014; Islam et al., 2018).

This study finding directed that the microbiological control measures in the farm practices is necessary to reduce the contamination in the farm level and to minimizes the public health hazards comparing with the non-CoP farms.

Antimicrobial residues was found in the broiler meat. However, the level of contamination in maximum cases under the desired level $(\leq 100 \mathrm{mg} / \mathrm{kg})(\mathrm{CAC}, 2012$ and Rahman et al., 1979). The farmers are motivated and aware to use unnecessary antibiotic, and they are following withdrawal period resulting a minimum level of contamination in their end product (broiler meat). 


\section{Conclusions}

Food safety control practices i.e. five plus five control measures in terms of microbial and chemical aspects found to be effective at the farm level in broiler production. In this regard developed food control guidelines to be implemented at broader aspect and it is necessitated to scale up throughout the country. This will benefit the marginal broiler farmers by adapting GHP and GAP in the farm practices.

\section{Acknowledgements}

We would like to convey thanks and gratitude to District Livestock Officers and Upazila Livestock Officers for their immense assistance to implement food safety program in the poultry value chain. Moreover, we would like to thank to Bangladesh Livestock Research Institute (BLRI), Savar, Dhaka and Department of Microbiology and Hygiene, Bangladesh Agriculture University, Mymensingh for accomplishment of sample testing against different parameters. Moreover, we are greatful to Lead farmers (LF) of respective Upazila for accepting COPs in broiler farming.

\section{Conflict of interest}

None to declare.

\section{References}

Ali ANMA, 2013. Food safety and public health issues in Bangladesh: a regulatory. European Food and Feed Law Review. 8: 31-40. C. Food Technol., 13: 437-444.

CAC, 2012. Codex Alimentarius Commission, Maximum residue limits for veterinary drugs in foods. Updated as at the 35th session of the Codex Alimentarius Commission (July 2012). CAC/MRL, 2-2012.

DLS , 2017. Department of Livestock Services, Bangladesh, Livestock Statistics for the year 2017.

Dolberg F, 2008. Poultry sector country review, Bangladesh. http://www.fao.org/3/a-ak069e.pdf.

Islam K, SML Kabir, AKMZ Haque, YA Sarker and MH Sikder, 2018. Molecular detection and characterization of Escherichia coli, Salmonella spp. and Campylobacter spp. isolated from broiler meat in Jamalpur, Tangail, Netrokona and Kishoreganj districts of Bangladesh. African J. Microbiol. Res., 12: 76170.

Kabir SML, MH Suman, MM Amin and S Yamasaki, 2014. Isolation, identification and antimicrobial resistance patterns of Campylobacter species from broiler meat sold at KR Market of Bangladesh Agricultural University Campus, Mymensingh. J. Agric. Food. Tech., 4:1-7.

Naurin S, MA Islam and MM Khatun, 2013. Prevalence of Salmonella in apparently healthy chickens in Mymensingh, Bangladesh. Microbes and Health, 1: 30-33.

NMKL, 1991. Salmonella bacteria, detection in foods. Nordic Committee on Food Analysis; NMKL method no. 71, 4th ed. Nordic Committee on Food Analysis, Oslo, Norway.

Rahman M, T Chowdhury, MM Rahman and W Hossain, 1979. Surveillance of Salmonella and Escherichia organisms in poultry feed. Bangladesh Veterinary Journal, 15: 59-62.

Ratananakorn L and D Wilson, 2011. Zoning and compartmentalisation as risk mitigation measures: an example from poultry production. Revue Scientifique et Technique-OIE, 30, 297.

Sarker YA, MM Hasan, TK Paul, SZ Rashid, MN Alam and MH Sikder, 2018. Screening of antibiotic residues in chicken meat in Bangladesh by thin layer chromatography. J. Adv. Vet. Anim. Res., 5: 140-145.

Sharma B, 2010. Poultry production, management and bio-security measures. Journal of Agriculture and Environment, 11: 120-125.

Shiramaru S, M Asakura, H Inoue, A Nagita, A Matsuhisa and S Yamasaki, 2012. A cytolethal distending toxin gene-based multiplex PCR assay for detection of Campylobacter spp. in stool specimens and comparison with culture method. J. Vet. Med. Sci., 74: 857-862.

Van Der Giessen H, H Sjoerd, JVD Wim, M Bas, PA Lemos, EP Mcfadden, G Sianos, JM Ligthart, D Van Essen, PJ De Feyter and PW Serruys, 2006. Indication of long-term endothelial dysfunction after sirolimuseluting stent implantation. European heart journal, 27: 166-170.

WPSA BB, 2017. Poultry for Nutrition Supply and Economic Development. The Daily Prothom Alo. A Round Table Disclosure.

Yunus M, EH Chowdhury and N Ahmed, 2008. A report prepared for Academy for Educational Development, Bangladesh Institute of Development Studies (BIDS), Academy for Educational Development. E-17, Agargaon, Sher-e-Bangla Nagar, Dhaka-1207. 